\title{
Examining Factors of Sports Brand Logo Design that Influence Purchase Intentions: Undergraduate Students Perspective
}

\section{Daniel Teng Jien Hao, Kit-Yeng Sin, Joanne Shaza Janang}

To Link this Article: http://dx.doi.org/10.6007/IJARBSS/v11-i4/9226

DOI:10.6007/IJARBSS/v11-i4/9226

Received: 07 February 2021, Revised: 10 March 2021, Accepted: 29 March 2021

Published Online: 26 April 2021

In-Text Citation: (Hao et al., 2021)

To Cite this Article: Hao, D. T. J., Sin, K.-Y., \& Janang, J. S. (2021). Examining Factors of Sports Brand Logo Design that Influence Purchase Intentions: Undergraduate Students Perspective. International Journal of Academic Research in Business and Social Sciences, 11(4), 901-914.

Copyright: (c) 2021 The Author(s)

Published by Human Resource Management Academic Research Society (www.hrmars.com)

This article is published under the Creative Commons Attribution (CC BY 4.0) license. Anyone may reproduce, distribute, translate and create derivative works of this article (for both commercial and non-commercial purposes), subject to full attribution to the original publication and authors. The full terms of this license may be seen at: http://creativecommons.org/licences/by/4.0/legalcode

Vol. 11, No. 4, 2021, Pg. 901 - 914

Full Terms \& Conditions of access and use can be found at http://hrmars.com/index.php/pages/detail/publication-ethics 


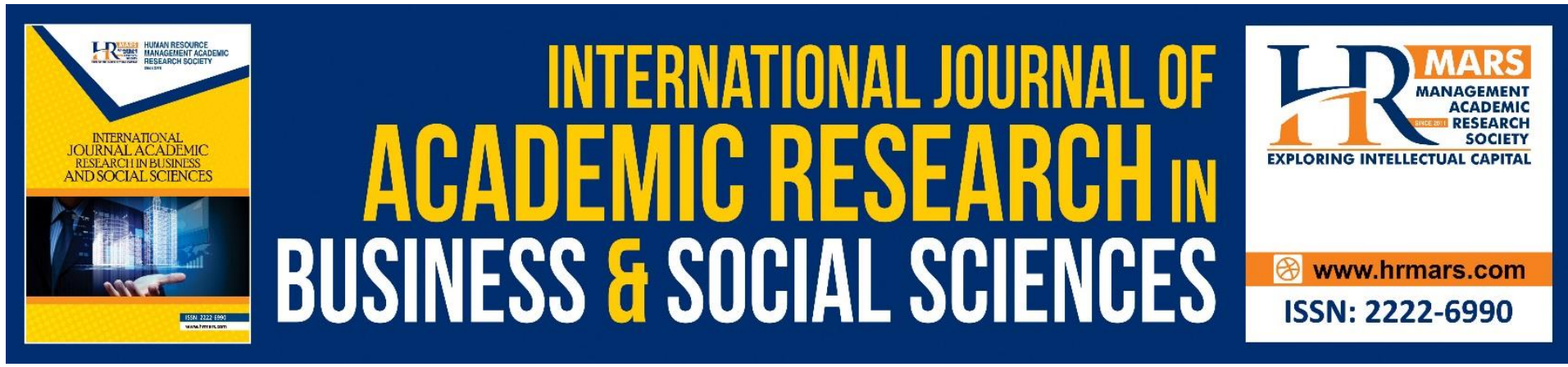

\title{
Examining Factors of Sports Brand Logo Design that Influence Purchase Intentions: Undergraduate Students Perspective
}

\author{
Daniel Teng Jien Hao, Kit-Yeng Sin, Joanne Shaza Janang
}

University Malaysia Sarawak, Faculty of Economics and Business, 94300 Kota Samarahan,

Sarawak

\begin{abstract}
Logo is vital for a company as it plays the huge role for the growth of business. Every company owner needs and desires their organization to be recognisable and boost the profit of company well. To achieve an impressive success in this competitive and challenging market, they must be one step ahead of their competitors. Thus, a company's meaningful logo can have a major effect on the market and attract new customers to boost revenue. As logo is the essentially branding tool, it is a company's or business's first point of communication and exposure with the world. This research study demonstrates the Signalling Theory which indicates the relationship between colour combination, shapes, lines and fonts used in logo towards purchase intention in sport's brand product from University Malaysia Sarawak (Unimas) undergraduate students' perspective. 374 questionnaires were distributed to respondents which are undergraduate students from Unimas for the purpose of testing and analysis of the hypotheses in this research study. The data collected was evaluated with the Statistical Package for the Social Sciences (SPSS) version 26.0. In this research, it was found that the shape of the logo and the line used in the logo had a major positive relationship with purchase intention towards sport brand product from Unimas undergraduate students' perspective, while the colour combination of the logo and the font used in the logo had a minimal impact on purchase intention towards sport brand product among Unimas undergraduate students. In contrast, the relatively insignificant impact of colour combination and font used in logo on sport brand product implementation tended to be influenced by other variables that yet to be determined.
\end{abstract}

Keywords: Logo, Colour Combination, Shape, Line, Font, Purchase Intention

\section{Introduction}

Nowadays, sports companies in the world are becoming huge businesses due to its wide existence across countries and high customer loyalty. Therefore, many sport companies invest so much in their logo by redesigning it to stand out from the other brands. According to human psychology, all the components of a logo such as shape of logo, the combination of colour, the line and font used in logo have significant impact on the view of the customers and the type of image they picture about a company's brand. As part of the visual image of a 
company, brand logos are crucial features of the brand for the identification, awareness and attraction of customers (Airey, 2009), especially in the beginning of a company.

Customer intention is among the most challenging and complex subject in the world of marketing. Customer intention is perhaps more flexible and dynamic than static and has been seriously affected by a variety of factors. One of the factors is brand loyalty, which affects customers to a greater degree through purchasing intention. Sports brand logo such as Nike, Adidas, Puma and many others are recognizable in the worlds. The logos of such companies, for the most part, instantly bind our thoughts to the company in question, even though we haven't seen the name, for instance, the black and white Nike's Swoosh logo which represent the speed (Avram, 2019). All of these are well-known sport brands, thus it is not surprising that people associate them with "strong" or "high-quality" sportswear (El Naggar \& Bendary, 2017). Even so, many people did not observe that local brands such as Banana Fighter, Livlola, Xierra and so on exist in the sports brand industry over the years in Malaysia. Therefore, the design of logo plays a vital role to enable the product being exposed to the market. In this context, logo is the first contact/trigger point of a company or business with the outside world as logo is fundamentally a conditioning tool. As a result, their logo must instantly convey who they are and what they do. If there is no existence of logos and branding, there would be no simple way to say who the customers were purchasing from. If customers engage to the branding, the chance is that they will be more receptive to whatever they are offered. From evaluating the brand recognition and ability to understand what makes a great logo, the company needs to consider making the appropriate design choices and handle the design process well.

Under these circumstances, researcher intended to examine the factors of logo design influence customer's purchase intentions in sport's brand product from Unimas undergraduate students' perspective. This research topic is being conducted which is an intent to stimulate insight about the logo design. Thus, the objective of this goal is to fully understand how logo design influence the customers' purchase intention.

\section{Literature Review}

Purchase Intention

Dodds et al. (1991) indicated that the purchasing intention was a willingness for customers to purchase a product or service. According to Blackwell et al. (2001), the purchasing intention would require a conditional decision on potential behaviour. Purchase intention is what we would intend to purchase in the future. Shao et al. (2004) indicated that the purchasing intention relates to an effort to purchase the product or to enter the shop that provides services. One of the purchase decisions of an individual with the reason that enables customers to purchase could be used to specify the buying decision (Shah et al., 2012). According to Lin \& Lu, 2020, needless to say, the buying intention is what products or services the consumer is willing to buy and desire to purchase. It is also interpreted as 'the act and physiological process of purchasing of a product. Past studies have shown that the likelihood of purchasing product increases is directly attributable to an improvement in purchase intention (Martins et al., 2019). Most companies have also used it for the goal of maximizing income from a particular commodity.

\section{Colour Combination}

Colours are used to provide a significant impact on perception and thus colours of logo design are playing significant role. The appropriate colour combination is a major factor in 
generating the illusion required to affect the decision of products and brands (Gofman, 2010). Fairchild (2013) stated that colour contains three major features which are hue, saturation or lightness and chroma. Therefore, these three elements will define how customers recognize the combination of colour and hence the associations they develop by doing so. Brand recognition is the ability of the customer to perceive or identify a product with a brand. Marketers shall create brand identity by applying a particular ideal of colours' combination to form a logo.

The relationship between colour combination and purchase intention

Colour helps to develop the identity of the brand. It also expresses the personality traits of a brand or brand image. Through this context, colour is a hidden language. Colour plays a significant information source when people verdict a buying decision. According to Kumar (2017), colour visualization provides a mechanism of defining possible colour combinations of logo for new brands or products and enhancing the distinction of products within a visually congested competitive market. So, companies use colours for their logos designs not only because they look great, but also because they reflect particular product or service qualities.

H1: There is positive relationship among the shape of logo and the customers' purchase intention of sport's brand product.

Shape

Henderson and Cote (1998) have mentioned 13 different design measurements and the shape is among them. Logo shape is especially significant to this study as the customer's responsiveness to the logo shape is determined. Turning to the dimensions of responsiveness, they are all under the jurisdiction of customers which included awareness, impact and sense. Empirical paper of the researcher outlined the mechanisms of pyschologic that link the esthetic aspects of stimulation to the perceptions of people (Berlyne, 1960). According to Arnheim (1974), shape is an essential part in the perception of customers.

Study has also shown that customers specifically distinguish among two versions which are rounded shape and angular shape with the same stimuli (Hogg, 1969). Although there is an apparently unlimited number of potential shapes, mentioned earlier, shapes could well be categorized either circular, angular, or a combination of both elements. According to Zhang, Feick, and Price (2006), objects with angular shape were more favourable to persons with an autonomous self-construction that is correlated with a combative attitude to resolving conflict, and objects with circular shape appeared to be more appealing to persons with the mutually dependent self-construction which correlated with a compromised attitude to problem solving. Customers visualise the rounded version of the stimulus as a contrast between the focused stimulant and the environment. Generally, roundness is correlated with approachability, sociability, and peace. In comparison, angularity is correlated with strength, power, and energy (Berlyn, 1976).

The relationship between shape and purchase intention

According to Peterson, AlShebil and Bishop (2015), the right shape used in logo will create the interest and attention of customers towards it which also linked with purchase intention. Marketing study before has proven softness associations will be activated by circular shapes, while hardness associations will be activated by angular shapes. Even so, Jiang, Gorn, Galli and Chattopadhyay (2016) have observed that such associations go well 
beyond the physical consistency of a product, people not only associated round logos with structural softness, but also the logo that has round shape or angular shape have the ability to concoct complex associations. For instance, a circular logo may invoke associations linked to soft texture, involving perceptions that a company is caring, pleasant, and responsive to consumer demands.

$\mathrm{H} 2$ : There is positive relationship among the colour combination of logo and the customers' purchase intention of sport's brand product.

Line

Logos are 2D forms of wide range, with inner and outer contour lines that are not inherently related. Consequently, the process of awareness appears to be challenging due to its complication. Several researchers explored the challenge of logo recognition through implementing algebraic and abstract variables (Doermann, Rivlin \& Weiss, 1996). While some quite successful findings were reported for smooth logos, implying high resolution images and proper segmentation of the logos throughout the report, they can difficultly be robust for compromised logos, such as strips that cover the logo in unpredictable place. In order to build a logo recognition strategy that is resilient to be using within noisy environments and provides instinctively appropriate performance, a redesigned Hausdorff Distance (LHD) line segment is recommended for logo recognition (Chen, Leung \& Gao, 2003). This new method has the benefits of integrating architectural and geographical data to measure the difference among two sets of line segments instead of two sets of points. Additional details could narratively offer greater and stronger recognition capabilities.

Relationship between line used in logo and purchase intention

According to Leung (1990), the conceptual logo recognizing framework consists of three components, for example segmentation, logo representation and matching. Line segment generation is able to extract the feature points from the contour lines and attaching any two subsequent feature points in a single reference line to reflect the image. The more reference lines there are, the larger the scale of the databases and the frequency of the simulations, but there would also be more possibilities for logo awareness (Gao, 2000).

H3: There is positive relationship among the type of line used on logo and the customers' purchase intention of sport's brand product.

Font

In these days, a lot of typographical works have been utilized to reflect or provoke specific feelings and emotions throughout the audience. Numerous typographical components, like type style can be used to express or elicit the ideal feelings. In order to produce different emotions related to typographical works, designers must fully recognize the interaction between emotion and typeface. They should effectively choose and manage elements such as shapes, colours, texture and visuals to raise customers' perceptions and emotional feelings to typographical works. To gain the interest of viewers, typographic designers had started to examine several areas similar to design in the quest for strategies to enhance the interaction process between designers and customers. Desmet \& Hekkert (2002) stated that typographic designers initially investigated the connection between design and emotions with regard to direct contact between the customer and the designer facilitated through 'form in motion.' The researchers believed that typography which has motion is a kind of 'emotion in type or typography,' as its time-based structure enables it to express 
cinematically expressions. Tantillo et al (1995) discovered that serif fonts such as Times New Roman, Georgia, Garamond, Baskerville, and Courier New were seen as graceful, charming, sentimental, distinct, lovely, and fascinating. Sans serif style fonts, for example, Arial, Calibri, Helvetica, Futura and Proxima Nova were perceived to be manly, strong, knowledgeable, noisy, understandable and upper class.

According to Camnalbur \& Mutlu (2011), a number of researchers have investigated the impact of differences in font characteristics on readability. The typography of trying to present personalities on logo is as crucial as having a major effect on the readability of the paper. Even so, there is considerable confusion about what type of font are more appropriate for logo (Camnalbur \& Mutlu, 2011). Many fonts will be much more readable than others on the display, according to previous studies. For example, a classic font like Times New Roman is known to be one of the most legible on display, however its size in screen resolution is far too small and the shapes seem unnatural.

The relationship between font used in logo and purchase intention

According to Henderson, Giese \& Cote (2004), when familiarity with the brand is poor and knowledge is minimal, the characteristics of the type of font such as organic, harmonious, elaborate, weighty and prosperous will affect the perception of the brand's personality. Since font is a communication tool, it is aimed for general use; that is, not just by experts or specialists in the area of graphic design. Many typeface and fonts have the potential of degree of emotional. Thus, 'font or emotional typography ' will be immediately visible to customers. People should understand the psychological concerns of a typographical concept as long as they observe it. Nevertheless, the classification of typography does not contain complicated typographical adjustments that can only be understood by experts.

$\mathrm{H} 4$ : There is positive relationship among the type of font used on logo and the customers' purchase intention of sport's brand product.

\section{Signalling Theory}

The signalling theory aligns in this research as it seeks to evaluate how the factors of logo design features affect customers' purchase intention towards sport brand, which will essentially lead to quality purchase decision and appropriate sport preference and selection. The theory indicates that when it comes to purchasing, the customer is looking for stimuli to get information. In the same way, customers are looking for stimuli from which to obtain information while searching for sport brand's product. Information influences the decisionmaking of customers in households, companies and governments. Decisions made by customers is on the basis of publicly available information, while private information which is accessible to only a minority or certain group of the people. Logo cues act as prompts for the customer to acquire information and to infer the product quality. According to Spence (2002), the signalling theory is inherently linked to the reduction of the asymmetric information between two parties. The company should select appropriate signals based on the attributes of the material, for example the attributes of the brand that are relevant to the estimation from the perspective of customers. Even so, it is often not possible for the customer to approximate the quality of these features with assurance. Lastly, customers who are satisfied are more likely to make the purchase from a specific sport store. On the other hand, sport store who does not fulfil the satisfaction of customers may lead customers to have a stronger intention of going to other stores. In the purposes of this study, quality corresponds to the 
underlying and unmeasurable potential of a signaller to accommodate the expectations or requirements of the customers examining a message that brought from the logo.

\section{Research Methodology}

The proposed research approach included a survey investigating how factors such as colour combination, shape, line and font used in logo design affect consumer purchase intentions in sports brand products from the perspective of Unimas undergraduate students as displayed in Figure 1. The online survey method which is quantitative research was used in this research study to collect data and was circulated to the respondents. Since then, conventional paper-pencil questionnaires are being replaced by computer-supported surveys. Internet questionnaire encourage messages to be sent directly to the targeted respondents, regardless of their geographical position. The online questionnaire was consequently collected for the analysis of the results of the quantitative data. The questions are classified and specified under the independent variables addressed in the literature analysis. There were over half of the items in this survey were constructed particularly for this analysis based on literature from scholarly journals, newspapers, and articles and books.

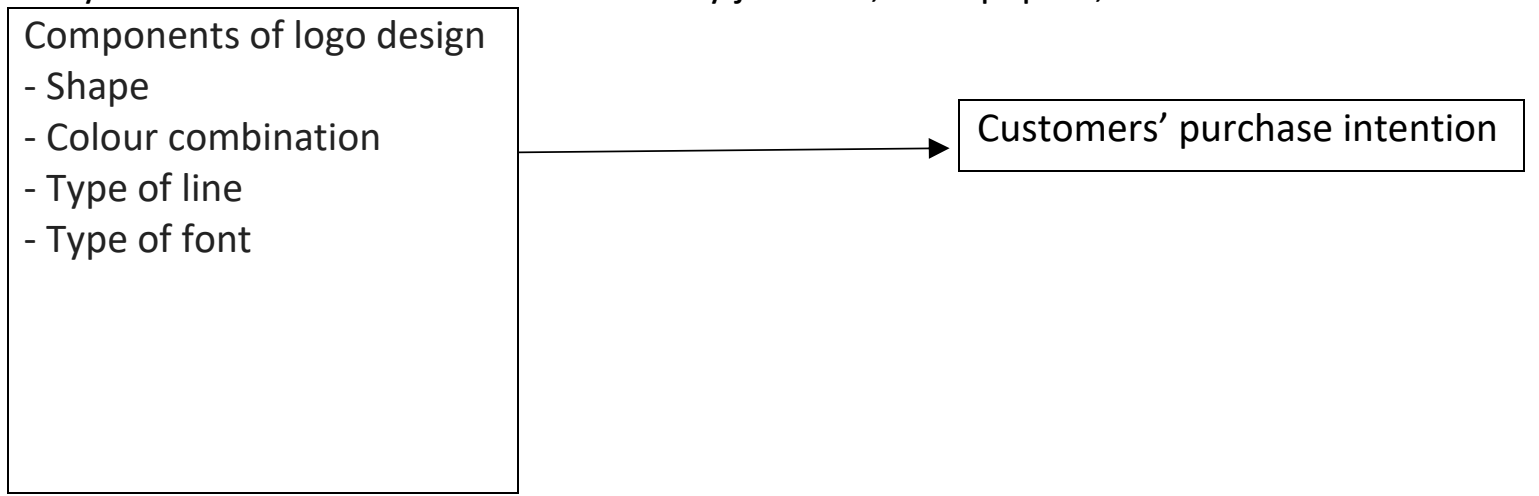

Figure 1 : Conceptual framework

This study analysis was carried out in UNIMAS to examine the logo design factors affecting the purchasing intention for sports brand products among UNIMAS undergraduate students. For the intention of collecting data and information of this research, UNIMAS undergraduates were being assigned as sample population and are expected to respond to the questions that given in online survey. According to the official web page of Unimas, there are a total number of 13,517 undergraduate students presently enrolled in ten separate faculties. The respondents are from Faculty of Economic and Business (FEB), Faculty of Computer Science \& Information Technology (FSSIT), Faculty of Engineering (FE), Faculty of Medicine \& Health Sciences (FMHS), Faculty of Cognitive Sciences \& Human Development (FCSHD), Faculty of Applied \& Creative Arts (FACA), Faculty of Built Environment (FBE), Faculty of Social Sciences and Humanities (FSSH), Faculty of Language Studies \& Communication Studies (FLSCS) and Faculty of Resource Sciences \& Science Technology (FRST).

The formula of Krejcie and Morgan is presented as below:

Where

$$
n=\frac{x^{2} N p(1-p)}{e^{2}(N-1)+x^{2} p(1-p)}
$$

$\mathrm{n}=$ the sample size

$\mathrm{N}=$ population size

$\mathrm{e}=$ the proportion of sampling error or 0.05 
$x^{2}=3.841$ (chi-square of degree of freedom 1 and confidence 95\%)

$\mathrm{p}=0.5$ (proportion of pollution)

The calculation of the sample size in this research is demonstrated as below:

$$
\begin{gathered}
\text { Size of sample, } n=\frac{3.841 \times 13517 \times(1-0.5)}{\left[0.05^{2}(13517-1)+3.841 \times 13517(1-13517)\right]} \\
=373.5 \\
\approx 374 \text { respondents }
\end{gathered}
$$

The sampling method would have been represented by the use of the Krejcie and Morgan equation to select the lowest possible number of target participants in the study as from population to fill the online questionnaire that prepared. Thus, the sample size in this research study is 374 respondents.

\section{Analysis and Findings}

Reliability Analysis

The values of Cronbach's alpha of the dependent variables which is colour combination, shape, line and font are $0.701,0.775,0.712$ and 0.854 respectively. For the purchase intention which is the last variable, the Cronbach's Alpha value is 0.861 . In general, the overall Cronbach's alpha value of all 18 items is 0.908 which achieved the excellent level of consistency. As stated by Sekaran (2003), Cronbach's alpha coefficients for variables above 0.8 , reflect excellent instruments.

Table 1: Reliability analysis

\begin{tabular}{|l|l|l|}
\hline Variables & Number of items & Cronbach's alpha \\
\hline Colour combination & 4 & 0.701 \\
\hline Shape & 4 & 0.775 \\
\hline Line & 2 & 0.712 \\
\hline Shape & 4 & 0.854 \\
\hline Purchase intention & 4 & 0.861 \\
\hline
\end{tabular}

\section{Descriptive Test}

Purchase intention is dependent variable in this research, while the shape of the logo, the colour combination of the logo, the line used and the font used are independent variables. Table 2 below presents a descriptive analysis of every dependent variable with a total of 374 graduates of Unimas. With the mean of 4.2059 and a standard deviation of 0.82056 , the analysis discovered that the highest mean is "Colour combination of sport's brand logo catches my attention and interest." Conversely, "I will purchase the sport's brand product if the colour of logo is bright" which is also the item for Colour combination have the lowest mean of 3.2968 and the standard deviation of 1.01735 . 
Table 2: Summary of Descriptive Test

\begin{tabular}{|c|c|c|c|}
\hline \multicolumn{2}{|l|}{ Variables } & \multirow{2}{*}{$\begin{array}{l}\text { Mean } \\
4.1765\end{array}$} & \multirow{2}{*}{$\begin{array}{c}\begin{array}{c}\text { Standard } \\
\text { deviation }\end{array} \\
0.82902\end{array}$} \\
\hline \multirow[t]{4}{*}{$\begin{array}{l}\text { Colour } \\
\text { combination }\end{array}$} & $\begin{array}{l}\text { Colour combination of sport's brand logo catches } \\
\text { my attention and interest. }\end{array}$ & & \\
\hline & $\begin{array}{l}\text { Colour combination of sport's brand logo is indeed } \\
\text { a great way to differentiate one brand from the } \\
\text { other. }\end{array}$ & 4.2059 & 0.82056 \\
\hline & $\begin{array}{l}\text { The involvement of colours in logo such as red, } \\
\text { yellow and orange produces an aura of energy and } \\
\text { strength. }\end{array}$ & 4.0321 & 0.90221 \\
\hline & $\begin{array}{l}\text { I will purchase the sport's brand product if the } \\
\text { colour of logo is bright. }\end{array}$ & 3.2968 & 1.01735 \\
\hline \multirow[t]{4}{*}{ Shape } & The shape of logo grabs my attention. & 4.1471 & 0.85538 \\
\hline & $\begin{array}{l}\text { The shape of logo provide information and details } \\
\text { about the product. }\end{array}$ & 3.9706 & 0.91264 \\
\hline & $\begin{array}{l}\text { The shape of logo defines the personality and the } \\
\text { identity of the organization. }\end{array}$ & 4.1310 & 0.83903 \\
\hline & I will remember the shape of logo. & 4.1684 & 0.89740 \\
\hline \multirow[t]{2}{*}{$\begin{array}{l}\text { Line used in } \\
\text { logo }\end{array}$} & $\begin{array}{l}\text { The systematic layout of the lines in logo enables } \\
\text { me to recognise sport brand products. }\end{array}$ & 4.0588 & 0.86750 \\
\hline & $\begin{array}{l}\text { I intend to shop whenever I come across appealing } \\
\text { and exciting displays of line in logo. }\end{array}$ & 3.7193 & 0.91681 \\
\hline \multirow{4}{*}{$\begin{array}{l}\text { Font used in } \\
\text { logo }\end{array}$} & My attention is drawn to the font style on the logo. & 3.8503 & 0.91987 \\
\hline & $\begin{array}{l}\text { Font give me motivation to take a deeper look at } \\
\text { the logo. }\end{array}$ & 3.8021 & 0.91949 \\
\hline & $\begin{array}{l}\text { Font style capture my curiosity and making it } \\
\text { easier to read. }\end{array}$ & 3.9358 & 0.87940 \\
\hline & $\begin{array}{l}\text { The font style of the logo will boost my purchasing } \\
\text { mood. }\end{array}$ & 3.6791 & 1.03750 \\
\hline \multirow[t]{4}{*}{$\begin{array}{l}\text { Purchase } \\
\text { intention }\end{array}$} & $\begin{array}{l}\text { I intend to buy sport brand products in the } \\
\text { upcoming years. }\end{array}$ & 3.8342 & 0.99290 \\
\hline & I will plan to buy the sports brand product. & 3.8262 & 0.96549 \\
\hline & I will consider the sports brand product first. & 3.8529 & 0.98093 \\
\hline & $\begin{array}{l}\text { I will give recommendation to others the sports } \\
\text { brand product. }\end{array}$ & 3.8610 & 0.99969 \\
\hline
\end{tabular}

Correlation Analysis

According to Puth, Neuhäuser \& Ruxton (2014), the purpose of using Pearson's correlation which is an analytical tool is to determine the magnitude of the relation between two or more continuous variables. Variables have a correlation where these parameters are influenced when a continuous variable is altered (Sabilla, Sarno \& Triyana, 2019). The colour combination of logo and the purchase intention have been determined that they have positive correlation $(r=0.411, p=0.000)$. There tends to be a moderate interaction as it is in the range of 0.30 to 0.49 . Based on the table 3 , the second correlation is the relationship between shape of logo and purchase intention and the findings had shown that they had a 
strong correlation with $r$ value of 0.522 . For the relationship between lines used in logo and purchase intention which is third correlation in this research study, they had a strong correlation after the analysis conducted. The $r$ value of both variables is 0.557 . There will have a moderate correlation between fonts used in logo and purchase intention which is included in the range of 0.30 to 0.49 . Based on the findings in this research paper, the correlation of both variables is analysed and they have the $r$ value of 0.431 .

Table 3: Statistics on correlations among all variables in this study structure

\begin{tabular}{|l|l|l|}
\hline Relationship & Coefficient of Correlation, $r$ & $P$ \\
\hline $\begin{array}{l}\text { Colour combination of logo } \\
\text { and purchase intention }\end{array}$ & $0.411^{* *}$ & 0.000 \\
\hline $\begin{array}{l}\text { Shape of logo and purchase } \\
\text { intention }\end{array}$ & $0.522^{* *}$ & 0.000 \\
\hline $\begin{array}{l}\text { Line used in logo and } \\
\text { purchase intention }\end{array}$ & $0.557^{* *}$ & 0.000 \\
\hline $\begin{array}{l}\text { Font used in logo and } \\
\text { purchase intention }\end{array}$ & $0.431^{* *}$ & 0.000 \\
\hline
\end{tabular}

** The significance of correlation is determined at the 0.01 level (2-tailed)

Regression Analysis

Multiple linear regression aims to study the correlation between multiple independent variables and a single dependent variable, which to estimate the value of purchase intention (dependent variable) from independent variables which are colour combination, shape, line and font.

Table 4: Regression analysis for correlation between dependent variable and independent variables

\begin{tabular}{|c|c|c|c|c|c|c|}
\hline \multirow{2}{*}{\multicolumn{2}{|c|}{ Model }} & \multicolumn{2}{|c|}{$\begin{array}{l}\text { Unstandardized } \\
\text { Coefficients }\end{array}$} & \multirow{2}{*}{$\begin{array}{l}\text { Standardized } \\
\text { Coefficients } \\
\text { Beta }\end{array}$} & \multirow[t]{2}{*}{$\mathbf{t}$} & \multirow[t]{2}{*}{ Sig. } \\
\hline & & B & $\begin{array}{l}\text { Std. } \\
\text { Error }\end{array}$ & & & \\
\hline \multirow[t]{8}{*}{1} & (Constant) & .592 & .242 & & 2.443 & 0.015 \\
\hline & $\begin{array}{l}\text { Colour } \\
\text { combination }\end{array}$ & .083 & .066 & .066 & 1.264 & 0.207 \\
\hline & Shape & .291 & .068 & .239 & 4.262 & 0.000 \\
\hline & Line & .342 & .060 & .325 & 5.722 & 0.000 \\
\hline & Font & .104 & .055 & .099 & 1.896 & 0.059 \\
\hline & \multirow{3}{*}{\multicolumn{3}{|c|}{ Summary of the result }} & \multicolumn{3}{|l|}{$R^{2}=0.375$} \\
\hline & & & & \multicolumn{3}{|l|}{$F=55.460$} \\
\hline & & & & \multicolumn{3}{|l|}{ Sig $=0.000^{b}$} \\
\hline
\end{tabular}

Note: Dependent variable: Purchase intention

Based on the table 4 above, the standard coefficient of colour combination is 0.066 , for the shape is 0.239 , for the line is 0.325 and the value of standard coefficient of font is 0.099. $R^{2}$ is the variance framework for the dependent variable which is purchase intention and it could be presumed from the independent variables include colour combination, shape, line and font used in logo. The result indicates that $R^{2}$ is 0.375 based on the table 4 mentioned 
above. This value indicates that $37.5 \%$ of the variance in the purchase intention can be expected by the colour combination, shape, line used in the logo and the font used in the logo style. The independent variables in this research study are statistically significant (Sig. $=0.000$ ) with the $F$ value of 55.460 , showing that the two variables which are shape and line used in logo make a significant cumulative contribution on purchase intention. The significant value which is $p$-value for colour combination, shape, line and font are $0.207,0.000,0.000$ and 0.059 , respectively.

According to the table 4 above, there were two variables which are shape and line had significant value of 0.000 . The $F$ value is very small which has the value of 0.000 as it is generally the Mean Square Regression divided by the Mean Square Residual and the correlation between the $p$-value. These values are commonly used to determine whether independent variables identify the dependent variable consistently. At the same time, the $p$ value is correlated with the alpha value (usually 0.05) and, if low, it can be inferred that the independent variable continuously assumes the dependent variable.

In conclusion, shape of logo and the line used in logo are positively and significantly impacted on purchase intention towards sports brand product among Unimas undergraduate students and hypothesis are accepted. Conversely, the factor of colour combination and font used in logo cannot be accepted as both of the $p$ value are greater than $0.05(p<0.05)$.

Overview of Hypothesis

Table 5: Summary of hypothesis testing results from Multiple Regression Analysis

\begin{tabular}{|l|c|}
\hline \multicolumn{1}{|c|}{ Hypothesis } & Remarks \\
\hline $\begin{array}{l}\text { There is a relationship between colour combination of logo and } \\
\text { purchase intention towards sports brand product among Unimas } \\
\text { undergraduate students. }\end{array}$ & Not Supported \\
\hline $\begin{array}{l}\text { There is a relationship between shape of logo and purchase } \\
\text { intention towards sports brand product among Unimas } \\
\text { undergraduate students. }\end{array}$ & Supported \\
\hline $\begin{array}{l}\text { There is a relationship between line used in logo and purchase } \\
\text { intention towards sports brand product among Unimas } \\
\text { undergraduate students. }\end{array}$ & Supported \\
\hline $\begin{array}{l}\text { There is a relationship between font used in logo and purchase } \\
\text { intention towards sports brand product among Unimas } \\
\text { undergraduate students. }\end{array}$ & Not Supported \\
\hline
\end{tabular}

Table 5 presents an overview of the results of the Multiple Regression Analysis Hypothesis Testing. The first hypothesis "There is a relationship between colour combination of logo and purchase intention towards sports brand product among Unimas undergraduate students" shows the not supported remarks due to the high p-value which demonstrates that the relationship between colour combination of logo and the purchase intention is less significant. Nevertheless, the second hypothesis in this research study which is "There is a relationship between shape of logo and purchase intention towards sports brand product among Unimas undergraduate students" had been accepted. For the third hypothesis, "There is a relationship between line used in logo and purchase intention towards sports brand product among Unimas undergraduate students" also had been accepted after the hypothesis test conducted. Lastly, the fourth hypothesis which is "There is a relationship between font used in logo and purchase intention towards sports brand product among Unimas 
undergraduate students" had a high value of $P$ value which means it not supported by the hypothesis test.

\section{Discussion and Conclusion}

Based on the analysed multiple regression result in this research study, it showed that the hypothesis between colour combination and purchase intention is not supported but both variables have a moderate correlation with the $r$ value of 0.411 and the significant value is greater than $0.05(p=0.207)$. This result can be supported by the empirical research of Kobayashi \& Benassi (2015) which stated that customers' affinity for logos does not appear to be influenced by colour, since colour is a single element in the characteristics of other logos. Many customers do not approve a brand of a single predominant colour, such as an orange or a low-contrast background colour. There appears to be a trend, therefore, to use at least two vivid background colours on the logo. Furthermore, generally, shape factors in logo are the most widely used factors for measuring the purchase intention of sports brand product. In this research study, shape under logo factors is analysed. Correlation analysis illustrated that the interrelation between shape and purchase intention towards sports brand product among Unimas undergraduate students is positive and significant where the $p$-value is 0.000 . Marketing studies had supported the hypothesis that specific connections are stimulated by circular and angular patterns. Likewise, Zhang, Feick \& Price (2006) denoted that the angle symbol is known to be more angular than the round symbol. The order of presentation of angular shape for stimulation and circular shape for stimulation is balanced. This result revealed that the angular shape of logo is more attractive and memorable than circular shape.

In this research study, the findings of multiple regression analysis had displayed that there is a positive and significant relationship between line used in logo and purchase intention towards sports brand product among Unimas graduate students. It has strong positive correlation among both variables as the $r$ value is 0.557 . According to Kim, Ko \& Lee (2012), the association among both variables can be seen from the frequency analysis of the researcher, the logo line has a clearer evaluations of the product than the Non-art line. The researchers found that presence of logo line will give higher perception of luxury which can lead to customers' possibility to purchase the product. This research reveals that enhanced perception of costly items contributes to more favourable evaluation results. If customers rate the product favourably, they are more likely to have a greater propensity to purchase. For the hypotheses testing, this research did not discover a significant effect of the font used in the logo on the consumer's purchasing intention, unable to accept the fourth hypothesis with the $r$ value of 0.431 and $p$ value is greater than $0.05(p=0.059)$. According to Shaouf, Lü, $\& \mathrm{Li}$ (2016), the findings suggested an insignificant association among the two variables ( $\beta=$ $0.05, p>0.10$ ). While the research could not show a clear and explicit influence of the font used in the logo on the purchasing intention. In contrast, the results reinforce the theory of signalling (Fishbein \& Ajzen, 1975), in which behavioural outcomes are thought to be strongly linked to attitudinal intentions. The signalling theory correlates in this study as it strives to measure the effect of the logo design influences on the purchasing intention of the customers for the sport brands, which would ultimately contribute to quality purchase decisions and adequate sport preferences and choice. Thus, this research study supports the Signalling Theory whereby this theory can show the relationship between the independent variables such as colour combination, shape, line and font used in logo towards the dependent variable which is purchase intention towards sports brand product among Unimas undergraduate students. In accordance with correlation analysis in this empirical study, even though colour 
combination of logo and font used in logo do not illustrate statistically significant effect towards purchase intention of sports brand product, but it cannot be assumed that both logo factors did not have impact on the purchase intention.

\section{Limitation and Recommendation}

There are some limitations in this research that should be defined for future studies. The lack of applicable and relevant factors also become difficulty in this research study. Since the researchers concentrated only on the factors in logo design, there were plenty of articles regarding colour combination and shape of logo but there is no applicable journals and publications of line and font used in logo provided. Few journals and publications may be similar to researchers, but most of them are out of date. Researchers find it difficult to find applicable papers and documents. Despite some details, the researchers noticed that the data had been corrupted and could not seek actual resources. Hence, this problem prohibits researchers from using the details as a reference point.

Although the data collected by questionnaire surveys which deviate from respondents' perceptions of logo design, it is advised that a range of approaches could be used to collect data from respondents in future studies. This research only uses quantitative techniques for further interpretation of the results. Nonetheless, this approach is tolerable in arithmetic calculation, but it may not be able to represent individual feelings or insights as numbers. It is encouraged that for future research; different approaches can be used for data collection, such as qualitative approach. In addition, the combination of quantitative and qualitative methods such as comprehensive interviews and group discussion can increase the effectiveness of the study. Moreover, it is recommended that the future researchers should extend the sampling frame. This research study focuses only on undergraduate students in Unimas. Therefore, researchers may perform studies in other cities or towns that has more population such as other states in West Malaysia in the future. This may be a big undertaking for researcher, but it indeed would help executives who plan to attract more customers of sports brand products. They will have the knowledge of logo design to avoid the unnecessary mistakes to have a unique and meaningful logo to represent their company. Apart from that, logo designer also will have a better idea to create the logo for the other related companies.

\section{References}

Arnheim, R. (1974). Art and Visual Perception: A Psychology of the Creative Eye. 1954. Artee. Berlyne, D. E. (1960). Conflict, arousal, and curiosity.

Berlyne, D. E. (1976). Similarity and preference judgments of Indian and Canadian subjects exposed to Western paintings. International Journal of Psychology, 11(1), 43-55.

Blackwell, D. R., Miniard, W. P., \& Engel, F. J. (2001). Consumer Behavior, South WesternThomson Learning. Mason. Ohio.

Camnalbur, M., \& Mutlu, D. (2011). Review about Font Typography on Instructional Design. In International Computer \& Instructional Technologies Symposium.

Chen, J., Leung, M. K., \& Gao, Y. (2003). Noisy logo recognition using line segment Hausdorff distance. Pattern recognition, 36(4), 943-955.

Desmet, P. M., \& Hekkert, P. (2002). The basis of product emotions. Pleasure with products, beyond usability, 60-68.

Dodds, W. B., Monroe, K. B., \& Grewal, D. (1991). Effects of price, brand, and store information on buyers' product evaluations. Journal of marketing research, 28(3), $307-319$. 
Doermann, D., Rivlin, E., \& Weiss, I. (1996). Applying algebraic and differential invariants for logo recognition. Machine Vision and Applications, 9(2), 73-86.

Gao, Y. S. (2000). Human face recognition using line edge information (Doctoral dissertation).

Leung, M. K., \& Yang, Y. H. (1990). Dynamic two-strip algorithm in curve fitting. Pattern recognition, 23(1-2), 69-79.

Henderson, P. W., \& Cote, J. A. (1998). Guidelines for selecting or modifying logos. Journal of marketing, 62(2), 14-30.

Henderson, P. W., Giese, J. L., \& Cote, J. A. (2004). Impression management using typeface design. Journal of marketing, 68(4), 60-72.

Hogg, J. (1969). Psychology and the visual arts: Selected readings.

Jiang, Y., Gorn, G. J., Galli, M., \& Chattopadhyay, A. (2016). Does your company have the right logo? How and why circular-and angular-logo shapes influence brand attribute judgments. Journal of Consumer Research, 42(5), 709-726.

Kobayashi, M. L., \& Benassi, M. D. T. (2015). Impact of packaging characteristics on consumer purchase intention: instant coffee in refill packs and glass jars. Journal of Sensory Studies, 30(3), 169-180.

Kumar, J. S. (2017). The psychology of colour influences consumers' buying behaviour-a diagnostic study. Ushus Journal of Business Management, 16(4), 1-13.

Lin, K. Y., \& Lu, H. P. (2011). Why people use social networking sites: An empirical study integrating network externalities and motivation theory. Computers in human behavior, 27(3), 1152-1161.

Martins, J., Costa, C., Oliveira, T., Gonçalves, R., \& Branco, F. (2019). How smartphone advertising influences consumers' purchase intention. Journal of Business Research, 94, 378-387.

Peterson, M., AlShebil, S., \& Bishop, M. (2015). Cognitive and emotional processing of brand logo changes. Journal of Product \& Brand Management.

Puth, M. T., Neuhäuser, M., \& Ruxton, G. D. (2014). Effective use of Pearson's productmoment correlation coefficient. Animal behaviour, 93, 183-189.

Sabilla, S. I., Sarno, R., \& Triyana, K. (2019). Optimizing threshold using pearson correlation for selecting features of electronic nose signals. Int. J. Intell. Eng. Syst, 12(6), 81- 90.

Sekaran, U. 2009. Research Method for Business, 5th ed, UK: John Wiley \& Sons, Ltd.

Shaouf, A., Lü, K., \& Li, X. (2016). The effect of web advertising visual design on online purchase intention: An examination across gender. Computers in Human Behavior, 60 , 622-634.

Shao, C. Y., Baker, J. A., \& Wagner, J. (2004). The effects of appropriateness of service contact personnel dress on customer expectations of service quality and purchase intention: The moderating influences of involvement and gender.Journal of Business Research, 57(10), 1164-1176.

Shah, S. S. H., Aziz, J., Jaffari, A. R., Waris, S., Ejaz, W., Fatima, M., \& Sherazi, S. K. (2012). The impact of brands on consumer purchase intentions. Asian Journal of Business Management, 4(2), 105-110.

Tantillo, J., Lorenzo-Aiss, J. D., \& Mathisen, R. E. (1995). Quantifying perceived differences in type styles: An exploratory study. Psychology \& Marketing, 12(5), 447-457.

Zhang, Y., Feick, L., \& Price, L. J. (2006). The impact of self-construal on aesthetic preference for angular versus rounded shapes. Personality and Social Psychology Bulletin, 32(6), 794-805. 